\title{
A Career at a Small Liberal Arts College
}

\author{
Jennifer Punt \\ Formerly Professor of Biology, Haverford College, Haverford, Pennsylvania 19041; currently Director of One \\ Health Research Education, University of Pennsylvania, School of Veterinary Medicine, Kennett Square, \\ Pennsylvania 19348 \\ Correspondence: punt@vet.upenn.edu
}

A career as a tenure-track professor at a liberal arts college provides the opportunity to combine serious interests in teaching with research. The basic goals of the liberal arts institution are to educate the student broadly while encouraging mastery of a particular area of interest. Preparing for such a career requires not only a commitment to teaching but also a productive $\mathrm{PhD}$ and postdoctoral experience, regardless of the expectations for active research within the job. The application and interview processes require one to be informed, flexible, energetic, and clear-in writing and in speaking. Establishing an invigorating teaching and research program will allow you to balance realism and ambition as you find a way to bring the best science to the undergraduate setting. The exposure to students whose thinking is often more unfettered and creative, and to colleagues whose scholarships span many disciplines, makes a position at a liberal arts college one of the most intellectually stimulating careers available to a scientist.

$M$ any young scientists have a keen interest in pursuing a career at institutions that focus on the education of undergraduates. These are referred to formally as baccalaureate institutions (as distinguished from research universities), and the most common institution in this category is the liberal arts college.

Largely an American invention, the liberal arts college offers a broad education to students usually between the ages of 18 and 22. Hundreds of institutions that focus on undergraduates are found within the United States; however, several countries outside of the United States (Britain, The Netherlands, Canada, Japan, etc.) have adopted variants of this model and more are likely to do so. Some U.S. liberal arts institutions are private (e.g., Allegheny College, Pomona College, Reed College), some are pub- lic (e.g., The College of New Jersey), some have current connections to religious organizations (Earlham College and the Quakers, St. Olaf's and the Lutheran Church), some have historical connections (Swarthmore and Bryn Mawr College were founded by Quakers), and many are secular (Amherst College). Most are coeducational, but some enroll only women (e.g., Smith, Barnard). Most have fewer than 3000 students, although some are considerably smaller than others (Pitzer College has just more than 1000 students; Wellesley has more than 3000).

In their ideal, liberal arts colleges educate the "whole student," exposing young adults to a breadth of educational opportunities that develop their intellects and prepare them to become thinking, working, governing citizens. This emphasis on breadth is accompanied by

Editors: Kaaren Janssen and Richard Sever

Additional Perspectives on Career Options for Biomedical Scientists available at www.cshperspectives.org

Copyright (C) 2017 Cold Spring Harbor Laboratory Press; all rights reserved

Cite this article as Cold Spring Harb Perspect Biol 9: a032789 
J. Punt

requirements for a depth of mastery and scholarship in a major discipline of choice. Although the general, overall mission of most liberal arts colleges is similar, their approaches, philosophies, and emphases vary. This is especially true in the sciences, where the emphasis on and resources for original research differ widely. At one end of the spectrum are colleges that are active undergraduate research institutions, where faculty and students both are expected to continually engage in original scholarly efforts. At the other end, are liberal arts colleges where active research is not a part of job expectations and may not be possible with the available resources. Most fall between these extremes and each college prides itself on an individual philosophy that is reflected in their curricular offerings and hiring preferences.

Regardless of these distinctions, and regardless of the emphasis placed on active research productivity among faculty, applicants with strong research backgrounds and active publication records have a real advantage. A clear commitment to teaching at the undergraduate level is critically important, of course, although the specific type of teaching experience a college will be looking for differs considerably from none to an expectation of formal in-classroom experience. Those who are most successful and happy in a career at any of the liberal arts institutions are those who derive energy from students and classroom engagement, as well as those who find ways to stay active in their fields, in whatever capacity they can.

\section{JOBS}

Jobs within a liberal arts college fall within a typical academic structure and are broadly divided into tenure-track and nontenure-track positions (see Fig. 1). Tenure was originally developed to protect a faculty member's position and autonomy from the whims of institutional donors and other decision-making members of an academic community. It is more narrowly perceived as a guarantee of employment for life, although it does not protect individuals for all transgressions. Often critiqued, it can inhibit an institution's ability to respond to professors who are underperforming. However, arguments

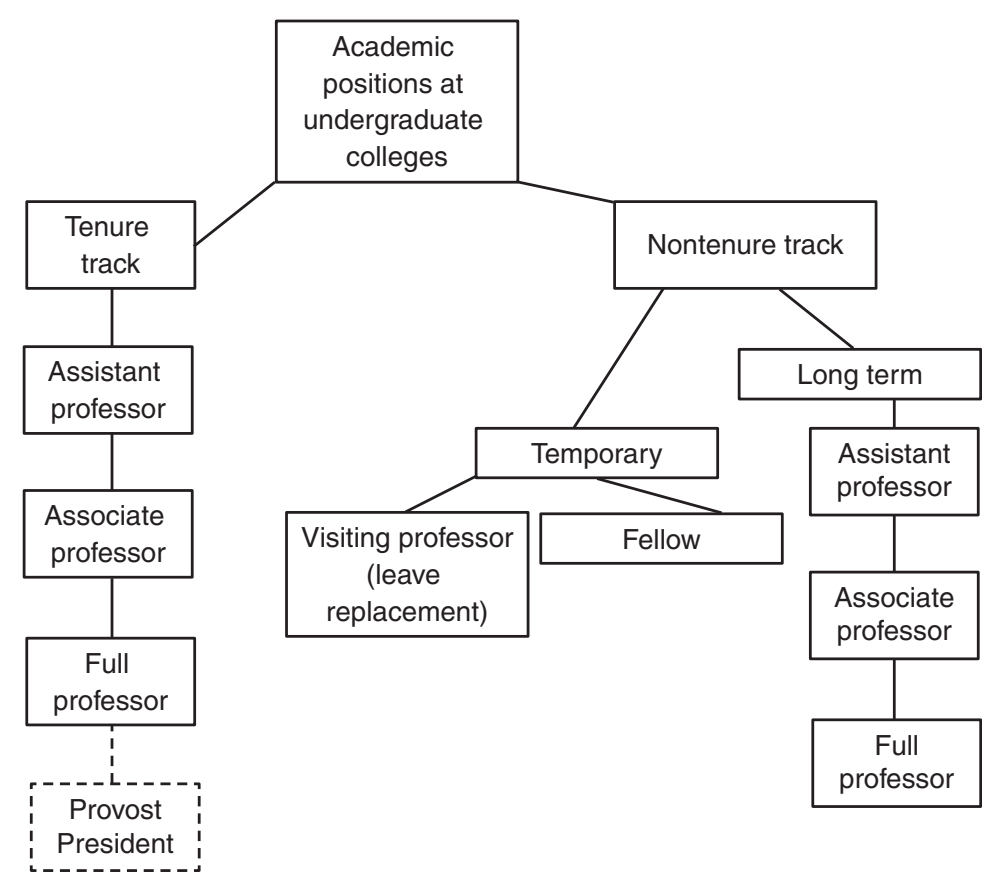

Figure 1. Schematic of academic positions. 
for its role in protecting academic freedom have trumped many attempts to dislodge it from academic traditions and tenure is likely here to stay for the considerable future.

\section{Tenure Track}

The positions along the tenure track provide the most autonomy, the greatest access to institutional resources, and potential job security. They progress from assistant professorships, to associate professorships, to full professorships. The teaching and research performance of all professors is thoroughly reviewed at defined intervals. A reappointment review often occurs in the third year. A review for promotion to associate professor, which is often accompanied by the granting of tenure, occurs in the fifth to the seventh years, and a review for promotion to full professorship often occurs in the 10th year (and beyond). A negative review at reappointment or at tenure review will mean a loss of a job (after a grace period). A negative view after tenure can have an effect on salary and access to resources (e.g., laboratory space).

\section{Nontenure Track}

Although they are not as secure and do not always come with the same privileges, nontenuretrack positions can also be rewarding. They can be temporary or permanent, part time or full time, and often vary with the history and needs of a particular department and institution. Visiting professorships are positions that fill sabbatical or maternity leave openings. They are temporary and can last as long as three years or more, or as short as a semester, depending on the needs of a department. Lecturer or instructor positions may also be temporary and typically have no expectation of or opportunity for research activities. Both of these types of positions offer opportunities for a young scientist to try on a liberal arts college job "for size."

Some nontenure teaching positions are also long term and virtually indistinguishable from a tenure-track position. These positions are often the products of historical anomaly rather than intentional hiring practices and are less dependable as job options. Each college uses its own terminology for these positions (e.g., "continuing appointment," "regular faculty") and you will have to verify the meaning of these by doing some research and asking questions.

\section{Administration}

Finally, faculty members can also assume more administrative positions, particularly in the later stages of their careers. Department chairs are usually tenured or full professors. Depending on the institution, these can either be long-term or rotating positions. Department concerns are shared by all faculty, but chairs coordinate the efforts and can take a key role in shaping the direction and ambitions of a department, and in some institutions play an important role in hiring decisions. Most faculties are also headed by a dean or provost, many of whom started their careers as professors who developed interests (and skills) in administration through their service. These are either selected from the internal faculty ranks or hired from another institution. They oversee faculty hiring, development, and academic programs. Presidents of colleges may also have held an academic position at another college or university, and typically have had previous substantive administrative experience (e.g., as a successful provost). They govern all programming and personnel-faculty, staff, and students-and are usually hired by and report to the institutional board of managers.

\section{SKILLS AND QUALIFICATIONS}

Perhaps the most frequent question asked by graduate students interested in a career at an undergraduate institution is, "Do I need a postdoc for a job in a liberal arts college?” If you are looking for a tenure-track professorial job, a $\mathrm{PhD}$ is absolutely required and postdoctoral experience is highly desirable. Where an active research program is an expectation, a postdoc (of two years or more) is a necessity. Even places where research programs are not as intense, and a postdoc not absolutely required, a strong, active research and publication record will give you a competitive edge as a candidate. 
J. Punt

There are several ways to infer a college's expectations of research activity. The institution's own website and that of the relevant science departments reveals much about their educational and research philosophy. The curriculum vitae of its current faculty, which are often available on the website, provide you with an excellent sense of research activity. Look at publication and funding records before and after the arrival of a faculty member to gain a sense of expectations.

College rankings serve as another indicator of research emphasis. These rankings are controversial within the academic world and should be viewed with the kind of scholarly skepticism that you have acquired during your training. U.S. News and World Report, perhaps the most influential rating agency, bases its rankings on multiple variables, including faculty and student resources, graduation rates, as well as the more intangible and arguably less reliable "reputation." The top ranked liberal arts colleges on these lists tend to emphasize active research in their programs; however, the correlation is not absolute. Other journals rank institutions differently and can offer additional insights. The Washington Monthly ranks institutions on the basis of their "contribution to the public good" and Forbes ranks institutions on their assessments of the overall value of the education received (including career prospects and debt incurred). Finally, the perspectives of current students, alumni, and colleagues will round out your understanding of institution expectations.

"What kind of teaching experience do I need to be competitive for a job in a liberal arts college?" is another frequently asked question. The answer also depends on the specific institution as well as the collection of your own experiences and your ability to communicate these. A successful application must clearly convey a genuine and thoughtful commitment to teaching and mentoring undergraduates. It should also provide evidence for teaching potential, which can take many forms, ranging from experience as a teaching assistant in a class as a graduate student, to teaching a class or two in any undergraduate setting, to actually holding a position as a visiting professor at a liberal arts college.
Do not underestimate the importance of your teaching statement, which is typically requested as part of your application. In this, you can thoughtfully describe your unique collection of experiences and aspirations as an educator.

Although many successful applicants to liberal arts colleges have never taught a full course or received formal student evaluations, few successful applicants have arrived with no experience with undergraduate research. How do you gain this? Opportunities to teach in a small college setting arise informally, via contacts that you or your supervisor have with college professors, or formally when colleges advertise (typically in the spring) for leave replacements. These visiting professorships provide rewarding and valuable experiences and can enhance your application considerably. However, it is important to recognize that they are designed to be temporary-not as a stepping-stone to a tenure-track position at that institution. If they remove you too long from research momentum, they actually can put you at a competitive disadvantage with other job candidates who are actively publishing at the time of the application. Avoid extending your visit beyond one or two years. Your expectations of and attachment to the institution can easily grow beyond what the position can offer.

Some colleges offer formal teaching fellowships specifically designed for postdocs interested in a career with undergraduates. These fellowships are sponsored by the National Institutes of Health (NIH), Howard Hughes Medical Institute (HHMI), and other private organizations (http://www.nationalpostdoc .org/careers/career-planning-resources/186postdoctoral-teaching-fellowships). The motivation behind their development is impeccable and the experiences can also be rewarding and valuable. However, similar caveats apply. Some teaching fellowships interrupt experimental momentum in ways that are hard to restore, putting you at a disadvantage with other candidates. The best programs are those that support a mentored teaching experience without requiring you to step away from your postdoctoral research training for too long.

"Should I develop a research program in a field that is more easily adapted to an under- 
graduate setting?" is an insightful question with a relatively simple answer. Although you should certainly be realistic about the resources that are required for research at an institution that does not have the same core facilities as a university, it is also critically important that you avoid shaping your scientific aspirations on the basis of anticipated limitations. Undergraduates can do more than some suspect and ambition is rewarded in the classroom, the laboratory, and if articulated well, among funding agencies. As we will describe below, substantive funding opportunities are, indeed, available to professors at undergraduate institutions. Institutions committed to faculty and student scholarship will also provide internal funding sources

\section{GETTING A FOOT IN THE DOOR}

The most important way to get a "foot in the door" is to apply for the job. Where are jobs at undergraduate institutions advertised? Most institutions will advertise in several places. The Science online Science Careers site is one of the best places to look (http://scjobs.sciencemag .org/JobSeekerX/SearchJobsForm.asp). Liberal arts college positions are also listed in the Chronicles of Higher Education (https:// chroniclevitae.com/job_search/new) and can be announced in online and paper publications associated with specific scientific societies. Several other online sites that assemble opportunities in higher education are also becoming more and more helpful. These include, but are not limited to, Higher Ed Jobs (https://www .higheredjobs.com/), Inside Higher Ed (https:// careers.insidehighered.com/), and Higher Ed Recruitment Consortium (HERC; https://www .hercjobs.org/). Many institutions want to enhance the diversity of their faculty and will list their jobs on sites that are directed specifically to individuals from underrepresented groups (e.g., http://www.minoritypostdoc.org/view/ resources.html). Finally, word of mouth is powerful: Let colleagues and supervisors know about your interest in this career angle.

What should be included in an application? The requirements are listed in the adver- tisement and typically include a request for a curriculum vitae, three outside letters of recommendation, as well as both teaching and research statements. It is ideal to get your application in no later than the date specified and to gently but firmly make sure that your outside reviewers also get their letters in on time. Applications that do not include all components may not be reviewed.

Who reviews the applications? The composition of search committees varies from institution to institution. Some are composed predominantly of department members, some include faculty members who are in allied departments in the sciences, and some include faculty outside the science divisions. Many committees at liberal arts colleges include undergraduates too. Each member, regardless of background, has a very important say in the fit of a candidate for a department and a college.

What are they looking for? Again, this depends on the philosophy of the institution, as well as the department; it helps to gain a sense of this before you apply. Regardless, energy, clarity, engagement, and genuine, informed interest are all features of successful candidates. Your teaching and research statements should be thoughtfully prepared and clearly articulated (share them with colleagues before sending them). The best research statements outline several possible projects that will be the basis for an independent scientific career. They also describe how undergraduates could participate in this development and contribute in original ways. They include recognition of the resources required, as well as an interest in developing the funding or support needed to garner those resources and answer the questions that interest you. The best teaching statements describe a candidate's experiences as well as their teaching philosophy. They include clear ideas for courses and approaches you are interested in developing (and why).

Applicants often ask how closely they need to fit the description of an advertisement. If, for instance, you are a biochemist, and the ad describes a position in cellular biology, will your application be considered? The more specific an 
J. Punt

ad is, the more unlikely it is that an applicant outside the field will be considered. However, if you are in an allied field and can clearly describe your connection to the field(s) described-and if your application is strong-you should certainly send the application in. Successful candidates do not always fulfill every descriptive requirement and a very strong application will be noted.

If you are short-listed by the committee, you will be asked for an interview. Some institutions may whittle a shortlist down even farther via phone interviews. These can be anxiety provoking because you and your interviewers cannot see or "read" each other; however, it is better to view them as liberating. Take advantage of the opportunity to take the call in any environment that you find particularly relaxing. The committee will ultimately offer on-site interviews to two to five candidates, who will usually be asked to prepare a research seminar and a teaching syllabus, or even a class. These candidates will meet with all members of the search committee and department, as well as students.

Prepare your presentations with an awareness of your audience. Will you be speaking to first year students? Majors? A variety? Faculty in the department? Faculty in other departments? Provost? President? If you are asked to give a seminar try to develop one that engages students and faculty who are not experts in your field, but also progresses to a level that would be appreciated by an expert. (This is a tall order, but a rewarding one. Practice!) The question/answer session after the lecture is more revealing than the lecture itself - this is where someone who knows their work and enjoys communicating science to students and faculty will shine, and be revealed to members of the committee.

If you are asked to give a class, develop a short outline, a set of slides, and/or a handout for the students. Do not pack your lecture with too many details or too many slides - give students time to digest a fact and put them into context. Do not be afraid to use a chalkboard or a white board-students often prefer this as an alternative to the rapidity of PowerPoint slides. Try to remember that "less is (almost) always more" and perfection is overrated.
What questions should you be prepared for? You are likely to be asked how you would design your research program with undergraduates, how you would contribute to and develop a particular course, and how you might be interested in contributing to other college-wide efforts. You may also be asked how you would help struggling students in a classroom, or how your undergraduate experience might inform your approach, where you think your field is going over the next decade, and what might be the greatest challenges you might face in the position. Do not be afraid to say you "don't know"-praise the question if it inspires you to think of something new and offer a brief, speculative answer. If students are involved, speak to them directly, as colleagues. Show an interest in the questioner and their experiences.

What questions should you ask? Speculative scientific questions that generate discussion are wonderful. But specific questions about the position that show that you are informed, thoughtful, and serious about the job are also welcome. How do professors balance teaching and research opportunities and expectations? How are professors mentored? Are faculty offered leaves? Course releases? How are they distributed? If the college has a robust research program, do students get credit for research in the laboratories? Do faculty get teaching credit for mentoring students in the laboratory? How are students attracted to the laboratories? What internal research resources are there? What external funds have been or can be attracted? Most importantly, questions should be asked out of genuine interest, not anxiety or strategy.

Above all, if you can, enjoy the process. Follow up with thank-yous and then relax. If you do not get the offer, do not take it personally. Those who are offered an interview are not just evaluated for their own prowess but for their academic "fit" in the department-a feature that you cannot always control. Your particular scientific bent or other research emphases may overlap too much with a potential colleague, for instance. Another candidate could unexpectedly synergize or fill gaps in appealing and unanticipated ways. It is impossible to anticipate all. 
Feel free to call the head of the search committee for feedback, and recognize that being shortlisted is a genuine accomplishment.

If you are offered the job, congratulations! You may want to make a return visit with a significant other to determine if you want to take the offer. And you will also have an important opportunity to negotiate for start-up funds and other resources prior to accepting the jobone of the only intervals in an academic career when you truly have the "upper hand." Although you should be gracious and respectful of an institution's limitations, do not be afraid to ask for what you really need. Develop lists of equipment that will really help you develop the best program for you, your colleagues, and your students. If research productivity is an important part of the job, funds to support a research technician for a year and a reduced teaching schedule in your first or second semester can help you hit the ground running.

Most institutions will give you two weeks or so to make a decision; try to respect this time limit.

However, if you are genuinely serious about the job and have real reasons to delay, ask for an extension. Do compare offers, but do not simply use an offer that you are not serious about to enhance another package. Small colleges are part of a small world.

\section{CAREER PROGRESSION}

The application process is the first of many evaluations that will span your career as a liberal arts college professor. Typically, you are given a three-year contract as an assistant professor; two to three years later, you are reviewed for reappointment, a process that determines if your contract is extended for future consideration for tenure. The reappointment process is often used as an opportunity for both you and the institution to enhance or correct your trajectory. If reappointed, you will be assessed for promotion to associate professor (which often is accompanied by tenure) sometime between your fifth and seventh year. At least three and often more years after this promotion, you will be assessed for promotion to full professor.
Typically, three types of efforts are assessed during each of these evaluations: research progress, productivity, and quality; teaching quality and innovation; and service. Teaching and research are arguably the most important elements of all evaluations, but service (or "citizenship"-contributions on committees, on outreach efforts, etc.) should not be dismissed.

\section{Teaching}

No matter how gifted a teacher one may be or have the potential to be, the learning curve in the classroom is very steep; the first two years will be the most exhausting (and exhilarating) as you develop the material you want to teach as well as your classroom delivery. Students are forgiving of occasional lapses in clarity if you are enthusiastic and responsive to their concerns, and bring a sense of self and sense of humor to the classroom. Getting students involved in the learning process is importantand much more easily said than done. "Clicker" technology is attractive to some, but technology is less important than on-the-spot engagement. Interrupting a lecture with a question that you allow students to discuss briefly, asking them to scribble a model or write down an answer to a problem can also involve and invigorate students, even in a large classroom.

Make time for your students. You will be given much advice about setting boundaries. Indeed, protecting your time and striking balances are important. However, the quality of your teaching and your students' educationand arguably your enjoyment of the job-is enhanced by a willingness to engage questions and concerns, sometimes even outside of standard office hours.

Take your students' input seriously-they can often see things more clearly than you and can be more direct in their concerns. Try to avoid feeling defensive and try not to internalize negative comments-dismiss them quickly if they are outliers, but respond to them in the next setting if they resonate with your and others' honest assessments. Enjoy the positive ones, always. 
J. Punt

\section{Research}

It should be clear by now that research expectations as a liberal arts professor vary widely. Some want you to be funded and actively publishing, although at a lower rate than at research universities. Some do not require active bench research at all. If active research is a requirement, how can you sustain a program without the resources offered by a university? Sheer will is an important first requirement, but other resources facilitate the effort.

\section{Funding}

Multiple agencies provide funding specific for faculty from small colleges. National Science Foundation (NSF) offers a Research at Undergraduate Institution (RUI) grant, which is evaluated for quality in the same pool as all other grants, but takes into account differences in resources, publication pace, as well as the educational bonus. The NIH R21 award is another granting opportunity specific for small college laboratories. Both NSF and NIH offer opportunities to fund equipment purchases and welcome proposals from groups of professors. Some scientific societies and private organizations can supplement your students' research goals with smaller awards. Finally, internal funds at some institutions can be a big help, especially early in your career. If your first grant does not succeed, speak to your program director, share your work with colleagues, and try again. Critique often enhances quality.

\section{Institutional Support}

Institutional commitment to resources that support research is also invaluable; it is difficult to work in an environment where your ambitions are the exception, even if you have funding. Ideally, institutions serious about research need to offer start-up funds; some existing facilities and the means to keep them up; matching costs for equipment requested in grants; personnel to help with grant preparation, submission, and instrument maintenance; funds for work-study and summer students; and a genuine expectation that all faculty maintain an active research program. In reality, some in- stitutions are in a position to offer more than others. However, even less-well-off institutions can support and inspire excellent research. Your own efforts are an important part of maintaining research quality, culture, and resources.

\section{Connection to Your Profession}

At a small college you are often more isolated from your immediate scientific colleagues, and it is important to maintain contact with your profession. Attend meetings at least once a year, serve on review panels, and give seminars at other institutions. Develop collaborations with colleagues at other universities. And bring your students to your meetings — ask them to present their work. This provides all of you with a unique exposure - and contributes to your balancing act by combining professional and educational ambitions.

\section{Service}

Throughout your career, you will be asked to assume department-wide and college-wide responsibilities in addition to your teaching and research efforts. Young professors are typically protected from too much service, which is often performed in committees. However, some committee work is worthwhile, exposing you to colleagues, experiences, and resources that enhance your development as a teacher and scholar. Some also inspire interests and opportunities that shape or alter your career goals. Be a good citizen when you need to be, be selective when you can be, and do not be afraid to embrace opportunities that excite you.

Who will evaluate your performance in these three categories? At each interval, an elected or selected committee of respected colleagues and administrative representatives (e.g., the dean or provost) will review an assembled portfolio of your accomplishments, as well as internal and external assessments of these accomplishments and make a recommendation to the president, who has the final word. Students, departmental colleagues, other faculty, and outside scholars will all be asked for perspectives. The weight given to each input varies with the institution and with the promotion 
under consideration. Tenure reviews are the most demanding, but in some institutions, reappointment and full professor promotions are as intensive. Familiarize yourself with the requirements and procedures associated with promotion at your institution, but do not overly strategize or politicize the process. High internal standards are often an excellent guide to success.

\section{Balancing Work and Family}

Careers at small colleges are considered by many to be "family friendly." It is true that a small institution can provide a community that is both receptive to and nurturing of the "whole faculty member" and their families, and it is also true that the autonomy of the job can provide you the freedom to be flexible with schedules. Nonetheless, it is important to understand that being a faculty member at a small college is a $24 / 7$ job that you cannot easily leave "at work.” Your grading, your course development, your mentoring, your research, and your guilt for not reading enough literature will often invade your family life-and vice versa. However, with energy and wisdom, attention to boundaries and flexibility, it can be done and you are likely to discover real rewards in the occasional synergy inspired by raising children and mentoring students. Remember that there is never one "right" time to grow a family; the choice is an important one and a personal one.

\section{WAY OUT}

Those who join the faculty of a small liberal arts college and receive tenure often stay in the position for a long time. However, some do pursue other opportunities. Most frequently, senior faculty who have developed administrative skills are attracted to provost or dean positions. Science faculty also assume leadership positions in government and private funding agencies. Some scientists who have maintained a productive professional profile are wooed by other academic institutions-other small colleges, research universities, or pharmaceutical companies. Regardless, the options one has depend on the record you have developed. They narrow considerably if your productivity and/or profile wane, particularly after tenure.

\section{BOX 1. My Experience}

In an unseasonably cold May of 1996, I was offered a job as tenure-track Assistant Professor of Biology at Haverford College, a small (1200 students) coeducational liberal arts college where the integration of research and teaching is valued highly. I could not have "chosen" a more intellectually stimulating or personally rewarding career, and know I have been very fortunate. From the first, I have been surrounded by ambitious, kind, and intellectually agile students, fascinating colleagues from within and outside the sciences, and a host of opportunities to challenge traditional boundaries.

Viewed from my CV, my route to this position seems linear. I graduated from Bryn Mawr College, with a major in biology at Haverford, where senior research was a requirement for all majors, not simply honors students. I did a research thesis with biochemical bent, and also became fascinated by immunology in an inspiring senior seminar course. I spent a year as a technician in an immunology laboratory at Stanford University, and then pursued a combined (VMD-PhD) degree program at the University of Pennsylvania, becoming a veterinarian and earning a PhD in Immunology. I did my postdoctoral fellowship at the NIH and got the job at Haverford in my fourth year.

However, the CV masks the dilemmas and serendipity that really marked my career progression. My veterinary background was a peculiarity that did not necessarily fit a career at a small college, and as a senior graduate student I seriously considered pursuing an interest in conservation genetics. Instead I was persuaded by an intellectually electric postdoctoral supervisor as well as by a budding relationship with someone whom I would eventually marry to pursue immunology and stay on the east coast.

(Continued) 
J. Punt

I was not yet in the "job market" when I received a call from what I now know was a partly desperate search committee at Haverford. They had made an offer that was turned down at the last minute and someone mentioned me as a possible candidate. I leapt at the chance, but knew it was a long shot. They were looking for a biochemist who could teach metabolic pathways. I was an immunologist who had once disliked metabolic biochemistry lectures. As a Haverford biology alum I was greeted with justifiable "suspicion" by newer faculty members concerned that I was driven by nostalgia. At one point, resenting the implication, I said with some pique, "I am coming here to start my career, not end it!" My very first gray hairs appeared after this interview and I was willing to walk away from the opportunity. I was told later that my feisty objection was a turning point in their view of my candidacy.

My NIH supervisor and fellow senior scientists were as distressed by the job offer as I was thrilled. One told me I was ruining my career by going to just a "teaching institution." My postdoc supervisor ultimately came around, however, and gave me some excellent advice. Negotiate for a good salary, he said. Gender-based income inequality can start at the beginning, when men are sometimes more willing to negotiate for higher starting salaries than women; the difference then simply compounds. Indeed, I had been happy to be offered less than I was making as a postdoc, but on his advice negotiated a modest increase.

The first year at Haverford was the hardest-I do not think I have worked as many hours at any other time of my life. I had a little girl and could only start preparing for lectures after she went to bed. I stayed up until 3:00 a.m. routinely and taught on fumes. But it was also wonderful. I learned more than I ever had as a student and slowly became a real teacher who not only desperately tried to deliver material to an audience, but began to craft it for the students, learning with them day by day. I came to understand that research is and always will be $75 \%$ troubleshooting and that pathological optimism is as important a skill as any other in the laboratory. By attending meetings, serving on study sections, taking advantage of collaborations, and by recognizing the talent and insights of my students, we developed a functioning and productive laboratory together. With results, publications, and student presentations at national meetings, I was able to "silence" those in my profession who assumed I would have to "drop out of research." I wrote my first NSF grant and was told it was "too ambitious." I wrote my second grant within two weeks of this news and have been funded ever since, although not without additional gray hairs. I had my second daughter prior to tenure and with the support of loving parents and stepparents, the two girls have grown into wonderful young women who speak with fondness about growing up in and around campus.

I was promoted with tenure in 2001, then to full professor in 2007. I have loved almost everything about the job (except grading) and almost every moment. There are times when the demands are exhausting and I admit that I have rarely taken the good advice about protecting one's time. Yet I credit a willingness to say "yes" for my most fulfilling experiences in the classroom, the laboratory, and with students. The best description I have for this career choice is that it offers you all the freedom in the world, but no time. And I could not recommend it more highly.

2017 update: I have now followed one of the career trajectories outlined for senior faculty by embarking on new educational and administrative ventures at Columbia University and now at the University of Pennsylvania (interrupted by two idyllic years teaching biology to high school students at an independent school). My background in education, research, and vet medicine served me and coalesced in ways I did not anticipate when I started at Haverford. What I have written about integrating research and teaching at a liberal arts college remains fully relevant, and the 18 years I spent in that setting remain one of the most wonderful two decades of my life. These shifts in career underscore how versatile one can remain-as well as how important family is in encouraging and promoting career flexibility. 


\section{BOX 2. Ten Dos and Don'ts}

1. Do engage yourself fully in a postdoctoral research experience.

2. Do apply when you have publication momentum.

3. Do take advantage of teaching opportunities but try not to sacrifice your development as an independent scientist, even if your position will not require active laboratory research.

4. Do become informed about the institution(s) to which you apply-know their resources, ambitions, "mission," and the full nature of the position.

5. Do bring enthusiasm and ambition to your interview, your students, and your job.

6. Do not just say things that you think your interviewers want to hear; be true to yourself and interested in them.

7. Do prepare a job seminar that can reach not only those in your discipline, but also nonscientists and students - and communicate to all why the work really matters and why it inspires you.

8. Do focus on teaching and research, but do not be afraid to say "yes" to other activities when inspired.

9. Do not "strategize" too much when applying for the job or preparing for tenure-your internal standards are often your best guide.

10. Do apply for external funds, remain engaged in your profession outside the college, and do not give up. 


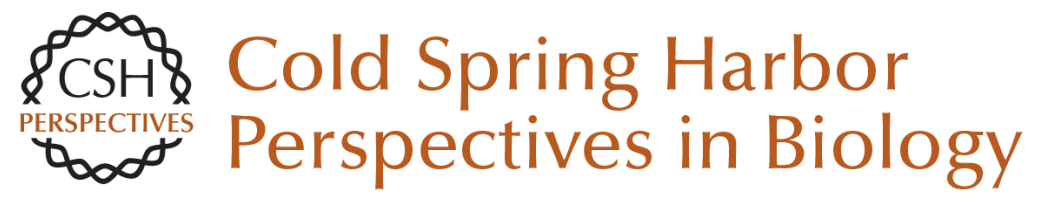

\section{A Career at a Small Liberal Arts College}

Jennifer Punt

Cold Spring Harb Perspect Biol 2017; doi: 10.1101/cshperspect.a032789

\section{Subject Collection Career Options for Biomedical Scientists}

\section{Careers in Science Publishing} John R. Inglis

Medical Communications: The "Write" Career

Path for You? Yfke Hager

At the Crossroads of Science and Society: Careers in Science Policy Amy P. Patterson, Mary E. Groesch, Allan C. Shipp, et al.

A Career in Patent Law: At the Cutting Edge of Science, but Not at the Bench Salim Mamajiwalla

Careers in Science and Grant Administration: View from the National Institutes of Health Marion Zatz and Sherry Dupere

Careers at Biotech Start-Ups and in

Entrepreneurship Susan Froshauer

Careers in Science Journalism and Writing Helen Pearson

\author{
Careers in Academic Administration \\ Lydia Villa-Komaroff \\ Working for a Scientific Society \\ Martin Frank
A Career for Life Scientists in Management Consulting Rodney W. Zemmel \\ Careers in Core Facility Management \\ Claire M. Brown \\ Leaving the Bench and Finding Your Foundation \\ John E. Spiro
A Career at a Small Liberal Arts College Jennifer Punt \\ Career Options for Scientists \\ Richard Sever and Kaaren Janssen
}

For additional articles in this collection, see http://cshperspectives.cshlp.org/cgi/collection/

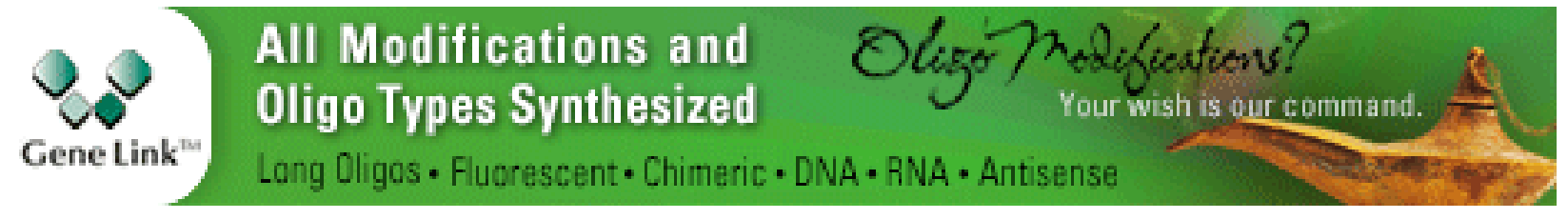

